\title{
MIGRAÇÃO DE CAPIXABAS PARA A AMAZÔNIA: NUMEROSIDADE E SUB-REPRESENTAÇÃO
}

Tiago Dalapicola ${ }^{1}$

\section{Resumo}

O artigo trata da migração de capixabas para Rondônia, iniciado nos anos do governo militar a partir de uma dupla frente, seguindo o modelo atração-repulsão. $\mathrm{O}$ artigo apresenta dados que corroboram com a hipótese da força do movimento, ao mesmo tempo que elenca as poucas obras que tratam do fenômeno, dando assim a dimensão da sub-representação do mesmo na literatura científica nacional. Trata ainda das causas e os efeitos dessa migração, especialmente para a área de destino desses migrantes. Por fim, sugere-se que em face da distância e dos fatores intervenientes presentes no percurso, os capixabas foram um dos grupos a dar maior contribuição de ordem socioeconômica e demográfica para Rondônia.

Palavras-chave: migração; marginalidade acadêmica; ligações privilegiadas; transformações socioespaciais.

\section{MIGRATION OF CAPIXABAS TO THE AMAZON: NUMEROSITY AND SUB- REPRESENTATION}

\begin{abstract}
The article deals with the migration of capixabas to Rondonia, initiated in the years of the military government following the attraction-repulsion model. The article presents data that support the hypothesis of a major migratory movement, while mentioning the few works dealing with the phenomenon, thus showing the under-representation of this migration in the national scientific literature. It also discusses the causes and effects of this population shift, particularly for the migrants destination area. Finally, it is suggested that, given the distance and the factors involved in the process, the capixabas would be one of the most socioeconomically and demographically contributing groups in Rondônia.
\end{abstract}

Key-words: migration; academic marginality; privileged connections; socio-spatial transformations.

\footnotetext{
${ }^{1}$ Licenciado e bacharel em Geografia pela Universidade Federal do Espírito Santo, com mestrado em Sociologia do Território (Società, território ed ambiente) pela Università Degli Studi di Trento, Itália, se interessa por estudos sobre população e desenvolvimento - transição demográfica, migrações, indicadores sócio-econômicos, teorias do desenvolvimento, planificação territorial e políticas sociais públicas. Doutorando em Geografia no Programa de Pós-graduação em Geografia da Universidade Federal do Espírito Santo, com foco em estudos do desenvolvimento.
} 


\section{MIGRATION DE CAPIXABAS VERS L'AMAZONIE: NUMÉROSITÉ ET SOUS- REPRÉSENTATION}

\section{Résumé}

L'article traite de la migration des capixabas vers Rondônia, initié depuis les années du gouvernement militaire suivant le modèle attraction-répulsion. L'article présente des données qui corroborent l'hypothèse d'un mouvement migratoire d'importance, tout en mentionnant les quelques ouvrages traitant du phénomène, montrant ainsi la sous-représentation de cette migration dans la littérature scientifique nationale. Il aborde également les causes et les effets de ce déplacement de population, en particulier pour la région de destination des migrants. Enfin, il est suggéré que, compte tenu de la distance et des facteurs intervenant dans le processus, les capixabas seraient l'un des groupes ayant le plus contribué socioéconomiquement et démographiquement à Rondônia.

Mots-clés: migration; marginalité académique; connexions privilégiées; transformations socio-spatiales.

\section{INTRODUÇÃO}

Os movimentos migratórios imprimem dinamicidade e acarretam variadas implicações que se materializam no espaço ${ }^{2}$ geográfico sob formas - veladas ou não, institucionalizadas ou não - de "(re)arranjos", "(des)ordenamentos"3 e políticas territoriais, conflitos.

Nesse sentido, o noroeste capixaba tem sido, nas últimas décadas, palco de movimentos migratórios importantes, especialmente no que tange à emigração. Investido na qualidade de centro regional, o município de Colatina-ES, bem como outros municípios, assistiu à partida de muitos de seus habitantes para o estado de Rondônia. Os dados dos censos demográficos realizados pelo Instituto Brasileiro de Geografia e Estatística (IBGE) a partir de 1960 sobre a migração interestadual no Brasil vieram ao encontro do observado em pesquisas de campo, reforçando a hipótese da significância de tal processo - de que em

\footnotetext{
${ }^{2}$ Compreendemos esse conceito a partir de Milton Santos, que nos apresenta o espaço enquanto "[...] algo dinâmico e unitário, onde se reúnem materialidade e ação humana. O espaço seria o conjunto indissociável de sistemas de objetos, naturais ou fabricados, e de sistemas de ações, deliberadas ou não. A cada época, novos objetos e novas ações vêm juntar se às outras, modificando o todo, tanto formal quanto substancialmente" (SANTOS, 2008, p. 46).

3 As aspas aqui ("') querem chamar a atenção para o fato de que "ordem" e "desordem" compõem sistemas de pensamento que se complementam. Logo, a partir das contribuições de Morin (2002) podemos entender que 'ordem' supõe determinismo, estabilidade, objetividade, regularidade, certezas, controle. Já a 'desordem' pressupõe o que não está inscrito na rotina; compõem atravessamentos; representa o inusitado, a divergência que, em sua gênese faz emergir o contraponto, a novidade. A "desordem", nesse sentido, possibilita a emergência de irracionalidade, ou, como lembra Milton Santos (2004), novas formas de ser racional.
} 
termos quantitativos o noroeste capixaba se constituiu como grande polo de emigração dirigida para o estado amazônico.

Após realização de um levantamento bibliográfico em diversas fontes - teses, dissertações e livros que tratam do Espírito Santo, mas especialmente no noroeste do estado, detectou-se que importantes transformações de ordem socioeconômica estiveram envolvidas no contexto de origem e de destino do fluxo migratório mencionado. No entanto, a temática tem sido marginalmente tratada. Dentre essas poucas e breves referências que tangenciam ou aludem a esse fenômeno, destacamos os trabalhos verificados em autores como Campos Jr. (2004), Mello \& Théry (2005), Binsztok (2006), Link (2004) e Jacob (2011).

O primeiro, Campos Jr. (2004), num estudo dedicado à formação e importância do município de Colatina enquanto centro regional do noroeste espírito-santense, relaciona o esgotamento do modelo produtivo da pequena produção agrícola à emigração verificada na zona rural, com afluxo destas populações, inicialmente, às áreas urbanas do município colatinense, e posteriormente para a Grande Vitória ou outros polos do estado capixaba, como também, de acordo com Campos Jr. (2004), para as bordas da Amazônia, em especial o estado de Rondônia.

Mello \& Théry (2005), por sua vez, focalizam em seu Atlas do Brasil a disseminação da lavoura cafeeira em Rondônia, apontando a presença de pequenos agricultores emigrados do Espírito Santo como responsáveis por essa introdução. Para além disso, no capítulo em que tratam das dinâmicas populacionais recentes do país, ao mencionar as ligações migratórias privilegiadas entre suas unidades federativas, destacam a presença dos capixabas no estado amazônida.

Binsztok (2006) abordando a questão da produção agropecuária no centro-sul de Rondônia, identifica duas construções sócio-espaciais diferenciadas dos produtores de café e outros gêneros alimentícios. Trata-se, segundo o autor, da presença de duas comunidades distintas, que apesar de ocuparem áreas próximas, apresentam especificações sociais oriundas de suas localidades de origem no Espírito Santo e que foram reproduzidas em Rondônia, no caso por capixabas descendentes de italianos e de germânicos. Ainda cita as relações preferenciais que existem entre os dois estados, principalmente no que tange ao comércio exterior de Rondônia, que se realiza por portos capixabas, mesmo quando são vislumbradas alternativas mais econômicas e dotadas de logística na própria região. 
Já Link (2004), ao abordar as implicações culturais, associa a imigração do grupo de camponeses capixabas descendentes de germânicos com o movimento de expansão do luteranismo na Amazônia Meridional. Outro autor, Jacob (2011) destaca a ligação específica entre o municipio de Vila Pavão, no noroeste capixaba e o município rondoniense de Espigão d'Oeste, alegando entre outras questões, influências como a dispersão da língua pomerana no estado do Norte.

Essas referências são importantes pontos de partida para problematização que anunciamos, porém, prescindem de uma contextualização mais ampla que situe as condições socioeconômicas e políticas nos quais o fenômeno aqui abordado aconteceu. Posto de outra forma, entendemos que nessas referências, mesmo com toda sua importância, o fenômeno da migração é tratado como algo dado, com naturalidade, fator esse que camufla problemáticas mais profundas.

Embora, como veremos ao longo deste elaborado, a migração de capixabas para Rondônia tenha causado efeitos significativos para ambos os estados, dada sua numerosidade e características dos migrantes, entende-se que ela é sub-representada. Essa sub-representação se manifesta tanto na forma dos poucos estudos empreendidos como também na forma de ausência na percepção popular ${ }^{4}$.

Os procedimentos metodológicos usados para a elaboração deste artigo pautaram-se na revisão teórico-bibliográfica já anunciada; consulta às matérias da mídia impressa que versaram sobre a temática em questão; entrevistas aplicadas a transeuntes entre os dois estados considerados e análise de dados do IBGE.

\section{Um necessário apanhado teórico geral}

A migração é um "fenômeno reflexo", ou seja, manifestação de processos e de transformações sociais e econômicas mais profundas, que lhe são subjacentes. Como bem lembra Moura (1980), configura-se assim como um tema sem essência própria, cujo objeto de interesse e tratamento não pode ficar predominantemente restrito a uma especialidade científica.

\footnotetext{
${ }^{4}$ Chamam muito mais atenção o caso dos migrantes oriundos dos vários estados do Nordeste no Centro-sul, ou o dos gaúchos (sulistas, em geral) que se dirigiram para o Centro e Norte do país, por exemplo. A esse propósito veja-se Becker (1997, p. 321), que faz menção a essas duas bem mais conhecidas facetas das migrações internas do Brasil.
} 
O fato de o estudo da migração não se constituir uma ciência em si, fica sujeito a uma forte vulnerabilidade, tanto no que diz respeito ao estabelecimento de seu conceito, que pode variar de acordo com a ciência onde se efetiva seu estudo, como no que concerne os métodos de análise e técnicas de mensuração empregadas, que embora enriqueçam a abordagem do tema, não deixam de imprimir vieses, distorções e forte grau de heterogeneidade às investigações realizadas, dificultando a comparação de resultados (MOURA, 1980).

No que tange à elaboração teórica-conceitual e considerando o tratamento dos dados levantados sobre migração, tem-se o problema da seleção da unidade atuante no processo migratório - no caso indivíduo ou família (grupo). Singer (1976) adverte sobre a capacidade de esses informantes reproduzirem com exatidão os motivos que os levaram a migrar e questiona quanto há de racionalização ou de estereótipo nas respostas, numa clara dúvida em relação à fidedignidade das mesmas.

A compatibilização entre níveis macro e micro de pesquisa é apontada por Póvoa-Neto (1997) como uma dificuldade básica, e, por conseguinte, motivo de preocupação. O autor lembra que vista como fenômeno social, a migração deve ser compreendida junto aos demais processos da sociedade, e que ao se optar por realização de inquéritos junto à indivíduos, estes podem não trazer em si a explicação dos processos vivenciados.

Desta forma, Singer (1976) caminha de encontro à Póvoa-Neto: a análise das informações coletadas, segundo o mesmo conduz a diagnósticos psicologizantes quando tomadas por referência a base individual, desfigurando ou omitindo condicionantes macrossociais. Assim, enquanto considerado processo social, a migração deve ter como unidade atuante para pesquisa o grupo e não o indivíduo (SINGER, 1976).

Patarra e Cunha (1987) apontam os dados como sendo uma das grandes dificuldades com que se depara o estudioso da migração. Citam como obstáculos as poucas opções de fontes, a periodicidade de algumas, a complexidade de outras, e até mesmo as limitações que elas apresentam quanto à percepção do fenômeno.

Um dos primeiros tratados sobre a migração surgiu no Reino Unido, no final do século XIX, a partir de uma provocação feita ao historiador-economista Ravenstein, de que "a migração parecia ocorrer sem qualquer lei definida". Assim, no ano de 1885, ele apresentou à Royal Statistical Society o artigo "The Laws of Migration", em que discorria sobre a migração em geral e determinou as sete leis que a governam. 
Lee (1966), afirma que apesar das críticas os trabalhos de Ravenstein resistiram à prova do tempo e continuaram sendo o ponto de partida de trabalhos teóricos sobre o assunto, lembrando que o próprio Ravenstein advertia que as leis da população e da economia em geral não têm em geral o mesmo rigor das leis físicas. O próprio Lee (1966) define-se migração como uma mudança permanente ou semipermanente de residência. $\mathrm{O}$ autor ainda emenda que não há limitações em relação a distância do deslocamento, ou à natureza espontânea ou compulsória do ato, nem distinção entre migração interna e externa. Entretanto, enquanto forma de mobilidade espacial, o autor afirma que migração não é sinônimo de nomadismo, seminomadismo e deslocamentos temporários para trabalho e férias, pois considera que "todo ato migratório implica num lugar de origem, num lugar de destino e numa série de obstáculos intervenientes"

Para Beaujeu-Garnier (1980) existem três grandes tipos de migração. A primeira é a migração de grande distância, ou internacional. Após, temos uma escala menor, dentro de países individualmente considerados, e a última, as migrações oscilatórias, que abrangem todos os movimentos nos qual o migrante não abandona o lugar de residência, a ele retornando periodicamente. A respeito do campo de forças que atuam sobre as migrações, Beaujeu-Garnier (1980) afirma que "uma causa de partida não é em si mesma suficiente, deve haver também algo para atrair os imigrantes. O fator de atração pode ser real ou imaginário."

Para o economista, demógrafo e sociólogo francês Alfred Sauvy (1979), os deslocamentos humanos e em grupo nem sempre são migrações. Para exemplificar, cita os refugiados frequentemente computados nas estatísticas de imigração, embora seu deslocamento seja involuntário. Percebe-se assim que esse autor ignora o fato de que independente de ser espontânea ou forçada, os refugiados têm motivos que os repelem e atraem, e que tanto sua saída como sua chegada trazem alterações para os respectivos polos de expulsão e atração.

Já para a Organização das Nações Unidas (ONU), em seu Manual VI, que trata dos "Métodos de Medição da Migração Interna", define migração como "o deslocamento de uma área definidora do fenômeno para outra, que se realizou durante um intervalo de migração determinado e que implicou em mudança de residência" (ONU, 1980).

\section{Causas da migração}


Para Castiglioni (1989, p. 22) "as causas que provocam o fenômeno migratório são extremamente diversas. O movimento não pode ser atribuído a uma causa única, mas à combinação de vários fatores". Entretanto, reconhece que

$$
\begin{aligned}
& \text { apesar da diversidade de causas, os trabalhos empíricos realizados ao redor do } \\
& \text { mundo levam a um resultado comum: os fatores econômicos são reconhecidos como } \\
& \text { os principais determinantes do processo migratório. As teorias atuais atribuem o } \\
& \text { principal papel às disparidades socioeconômicas entre as regiões. }
\end{aligned}
$$

Nesta direção, Sjaastad (1980) aponta que tanto as causas quanto a direção e intensidade da migração são reações dos migrantes em relação aos diferenciais de rendimentos que prevalecem espacialmente.

Os fatores que entram na decisão de migrar e o processo migratório são vistos por Lee (1980, p. 44) resumidos em quatro tópicos:

1) fatores associados ao local de origem;

2)fatores associados ao local de destino;

3) obstáculos intervenientes;

4) fatores pessoais.

Singer (1976) diz que as causas estruturais que impelem determinados grupos a se pôr em movimento são quase sempre de fundo econômico - deslocamento de atividades no espaço, crescimento diferencial da atividade em lugares distintos, etc - e atingem grupos que compões a estrutura social do lugar de modos diferenciados, ou seja, promove uma seleção. Beaujeu-Garnier (1980) argumenta que entre outros autores, é lugar comum dar ênfase ao descontentamento com a "sorte econômica", sendo que a maioria considera esta como a motivação essencial. Todavia observa que:

algumas migrações não são motivadas pelo desejo do lucro; a busca da liberdade política ou religiosa, seguida às vezes da necessidade de defesa de perseguição, tem sido responsável por emigrações em massa que muito contrariam os interesses econômicos dos migrantes.

A autora ainda elenca outras motivações para a migração, como a atração do grupo, em que indivíduos migram pelo sentimento de companheirismo pela família ou amigos, e o "espírito pioneiro" que procura não só um padrão de vida mais elevado, como também dificuldades a vencer, obstáculos naturais a superar e empreendimentos à desenvolver, como os sitiantes pioneiros que desbravam a borda das florestas canadenses. 


\section{Seletividade das migrações}

Os indivíduos reagem diferentemente diante dos fatores que induzem a migração (Castiglioni, 1989). Os estímulos para migrar são assimilados, nessa ótica, de acordo com vários fatores condicionantes, entre os quais a autora cita a idade, a instrução, a especialização, o estado civil, as aspirações pessoais e o sexo. Essa diferenciação se constitui numa das principais questões do estudo das migrações, a qual chamamos de seletividade.

Em Sjaastad (1980), que vê como principal causa das migrações a necessidade de equiparação de rendimentos entre regiões, a seletividade está relacionada com o potencial produtivo da população, desprezando dessa forma, crianças, idosos, incapacitados para o trabalho, grávidas, entre outros desprovidos de potencial de produção econômica, que não migram.

Nesse sentido, Singer (1980) afirma que há seletividade dos fatores de expulsão e dos fatores de atração, emendando ainda que num primeiro momento, a determinação de quem migra ou fica é social, ou de classe, e num segundo momento, as condições objetivas e subjetivas determinam quais membros dessa classe migrarão e quais permanecerão.

Para Castiglioni, a importância da seletividade presente nos movimentos migratórios está no fato que esta produz transformações qualitativas importantes nas regiões de partida e de chegada dos migrantes.

\section{As regiões envolvidas no processo migratório ${ }^{5}$ O Noroeste espírito-santense}

Ocupando uma posição periférica no cenário econômico nacional, a elite capixaba viu na incipiente industrialização promovida no Espírito Santo entre os anos de 1960/70 uma alternativa de se desvencilhar, mesmo que em parte, das amarras da dependência econômica em relação ao café, cuja imprevisível oscilação dos preços - de acordo com os ditames do mercado internacional - era prejudicial à economia local. Na década de 60, o GERCA (Grupo Executivo de Racionalização da Cafeicultura) elaborou um plano com o objetivo de reduzir a produção cafeeira.

A proposta era que fossem erradicados os cafezais antieconômicos. Assim, o plano de erradicação foi levado à cabo, e no biênio 1966/1967 foram destruídos em todo Brasil, 655 milhões de cafeeiros, que liberaram 674 mil hectares de terra. Somente no Espírito Santo,

${ }^{5}$ Nesse caso o termo região é usado em sua acepção não científica. 
foram destruídos 235 milhões de pés-de-café, o que equivale a cerca de $35 \%$ do total nacional, e liberados 293 mil hectares de terra (VALADÃO, 1999).

As terras liberadas nessa política de erradicação dos cafezais não ficaram livres para o pequeno agricultor, geralmente parco em recursos e que pratica agricultura de roça, associada à subsistência da própria família. Nos municípios ao norte do estado, principalmente na porção noroeste, mas não só aí, a terra foi empregada, basicamente, para pecuária, muito menos exigente em termos de cuidados (IBGE,1979), o que torna menos imperiosa a necessidade de mão de obra. Além disso, o fomento à eucaliptocultura, em idos dos anos 1980, começa a ganhar espaços cada vez maiores nas áreas que antes se prestavam à agropecuária, contribuindo, ainda mais, com “expulsão" de populações do campo.

Estava formado um cenário favorável à emigração de muitos camponeses capixabas. Além disso, fatores como as frequentes estiagens prolongadas, lotes de terra cada vez mais fatiados em virtude de sucessivas divisões familiares ao longo das gerações, concentração fundiária, desapontamento com as oscilações do mercado agrícola, etc, também impeliram saídas de homens e mulheres das zonas rurais capixaba, principalmente na porção noroeste.

Nesse sentido, Becker (1997) nos lembra que paralelamente à metropolização da costa oriental brasileira, surgiram focos de atração migratória em espaços até então marginalmente ocupados pelo capital. Assistia-se tanto a uma modernização e expansão da agricultura capitalista no Centro-sul, com a consequente concentração fundiária a que já fizemos aceno antes, como também a uma expansão da fronteira demográfica na Amazônia.

A análise dos dados do IBGE (1979) confirma as discussões até aqui construídas. No período 1960/70, a Microrregião de Colatina, município polo do noroeste capixaba, foi considerada uma área de fortíssima evasão apresentando altas taxas decenais de emigração. Essa mesma Microrregião foi em tal estudo classificada como "antiga área cafeicultora do Sudeste com introdução crescente de pastagens artificiais e menor importância de atividades ligadas a lavoura”. Além do município de Colatina, ainda são citados os municípios de Barra de São Francisco, Ecoporanga, Nova Venécia, Pancas e São Gabriel da Palha como fortemente expulsores de população.

Nesse contexto, aparece com bastante importância a emigração de capixabas para Rondônia. Esse fato se processa desde os anos 60 do século XX, com seu pico verificado entre os anos 1970/1980, mostrando que o sentido dessa migração se constituiu numa opção ao êxodo rural e numa forma de reprodução do mundo rural capixaba em terras amazônicas. 
$\mathrm{Na}$ análise de Becker (1997) sobre a mobilidade populacional no contexto da fronteira amazônica, encontrou-se subsídio para, nesse contexto mais amplo, enquadrar a migração estudada nesse trabalho. Ela se colocaria, segundo a autora, como um movimento de ocupação de espaços considerados "vazios", acompanhados de políticas governamentais fiscais e creditícias. O Estado na qualidade de ator, afirma ainda, teve papel de primeira ordem ao implementar um colossal sistema de infraestrutura viária e energética ${ }^{6}$ na Amazônia, como expressão do Programa de Integração Nacional.

\section{Rondônia $^{7}$}

Formado por terras anteriormente pertencentes aos Estados do Amazonas e Mato Grosso, o Estado de Rondônia foi originalmente criado como Território do Guaporé em 1943. A denominação atual foi dada em 17 de fevereiro de 1956, em homenagem ao Marechal Rondon, desbravador daquelas terras.

Entretanto, desde o final do século XIX, com o auge da exploração da borracha, a área passou a receber imigrantes nordestinos para o trabalho nos seringais. $\mathrm{O}$ início da construção da Estrada de Ferro Madeira-Mamoré em virtude da assinatura do Tratado de Petrópolis ${ }^{8}$ (1903), constituiu outro poderoso impulso para o povoamento da área que viria a se tornar no futuro o estado de Rondônia 9 .

O Marechal Rondon foi personagem de grande importância no processo de ocupação do estado, pois coordenou os trabalhos de execução da obra que possibilitou o acesso à região - a linha telegráfica. Em 1907, Rondon foi encarregado pelo Presidente da República, Afonso Pena (1906-1909) de ligar à capital, pelo fio telegráfico, os territórios da Amazônia, do Acre, do Purus e do Alto Juruá, por intermédio de Cuiabá, já em comunicação com o Rio de Janeiro.

Ao término dessa empreitada, a qual evidencia o interesse do Estado em garantir a posse da região amazônica, existia um corredor por terra que ligava aquela parte ao restante do país. Por ali, inúmeras famílias migrariam acompanhando o curso da linha telegráfica. $\mathrm{O}$ trabalho coordenado por Rondon, além de ter integrado essa região ao restante do país através do telégrafo, também realizou inúmeros trabalhos científicos que visavam o reconhecimento dela, como estudos etnográficos, mineralógicos e cartográficos. Rondon literalmente colocou

\footnotetext{
${ }^{6}$ Becker cita a construção das rodovias Transamazônica, Cuiabá-Santarém, Belém-Brasília, e a usina de Tucuruí.

${ }^{7}$ Os acenos históricos apresentados têm intenção de aludir apenas aos processos de ocupação mais recentes do estado de Rondônia, e não de exaurir suas discussões.

${ }^{8}$ Compensação à Bolívia pela ocupação do território do Acre.

${ }^{9}$ Disponível em http://www.rondonia.ro.gov.br/diof/sobre/historia/ Extraído em 15/12/18
} 
a região no mapa (LINK, 2004). Em 1981, o Território de Rondônia passou a categoria de Estado da Federação.

Rondônia possui atualmente 52 municípios, quase todos recentemente ocupados, com predominância econômica em atividades primárias. Conta com uma população de pouco menos de 1,8 milhões de habitantes, o que corresponde a uma densidade populacional de 7,5 habitantes por $\mathrm{km}^{2}$ (IBGE, 2017).

Nas últimas décadas o estado de Rondônia sofreu um intenso processo de crescimento populacional, cuja população é oriunda de diversas regiões do País. Esse crescimento populacional horizontal ${ }^{10}$ está associado à consolidação da presença do Estado na Região Norte, que segundo Bahiana (1991) faria parte de uma política oficial voltada para a problemática geopolítica e os objetivos do desenvolvimento e da segurança nacionais.

Numerosas levas de migrantes foram atraídas à área, dando origem a núcleos que hoje são sedes de municípios, como Cacoal, Ouro Preto do Oeste, Vilhena, Ariquemes e Ji-Paraná. Facilidades relacionadas à implantação de rodovias ou a distribuição de lotes de terra contribuíram para levar a cabo tal política oficial.

\section{A atração populacional}

O final dos anos 60 e a década de 1970 foram marcados por governos militares, ditatoriais. Uma das bandeiras desses governos era tornar efetiva a ocupação das porções periféricas do país, principalmente a Amazônia. Seria uma questão de soberania nacional, expressa no slogan "integrar para não entregar". O receio da ameaça estrangeira era constante. Santos (1994, p.52), numa análise marcadamente geopolítica nos diz

que havia o interesse por parte do poder público de incorporar efetivamente esses
territórios de fronteira ao espaço nacional. Os interesses por trás dessas intenções
são estratégicos, geopolíticos, econômicos, a partir da introdução de formas
empresariais de exploração econômica do solo.

Para efetuar a ocupação de tais áreas periféricas são oferecidos incentivos, notadamente a doação de terras, de sementes, assistência técnica, facilidades para obtenção de financiamentos bancários, etc. Criaram-se, com isso, as chamadas "fronteiras de expansão".

Castiglioni (1984) corrobora, registrando que a migração para Rondônia foi estimulada pela política de colonização das fronteira agrícolas, a construção de estradas, a existência de riquezas minerais e da então crença sobre a existência de terras altamente férteis,

\footnotetext{
${ }^{10}$ Também chamado saldo migratório: diferença entre imigrações (entradas) e emigrações (saídas)
} 
em consonância também com fatores fortemente repulsivos nas zonas agrícolas tradicionais das regiões mais povoadas: a mecanização da agricultura, a intensificação da pecuária, a agricultura de exportação - presentes em outras unidades da federação.

Os imigrantes que se deslocam para essas novas áreas funcionariam como desbravadores, desencadeadores das transformações econômicas pretendidas, após o que grandes grupos tenderão a deslocar-se espontaneamente para esses lugares (SANTOS, 1994). A leitura da autora caminha em direção ao enfoque neomarxista de Gaudemar (1977), que observa que migrar não é mais um ato soberano de vontade pessoal para equalização das diferenças de renda, mas sim uma mobilidade forçada para atender as necessidades do capital.

A população de Rondônia passa de 69.792 habitantes em 1960 a 111.064 em 1970 e 491.025 em 1980 - a taxa de crescimento mais elevada do Brasil. Não obstante, admite que a dimensão deste fenômeno provocou diversos problemas, como Castiglioni (1984, p. 52) nos coloca:

o surgimento fora de controle de núcleos urbanos, a ocupação de reservas indígenas, o desmatamento, incapacidade do governo de preparar a infraestrutura para acolher os fluxos crescentes e controlar a ocupação da terra por grileiros.

Em 1967/68, o governo divulgou a existência de terras férteis no Norte do país, enfocando especialmente o território de Rondônia. Também em 1967, o Instituto Nacional de Colonização e Reforma Agrária (INCRA) começou a gerenciar o assentamento de colonos.

Surgiram assim vários projetos de assentamento. Nos anos de 1970, o governo brasileiro criou o Programa de Integração Nacional. Através desse programa visava-se melhorar as condições da área do futuro estado de Rondônia "para a expansão do capital e para minimizar a crise de desemprego no Nordeste e no Centro-Sul, assentando, em projetos de colonização, migrantes dessas duas áreas".

A primeira tentativa de colonização em massa da Amazônia foi o assentamento de migrantes ao longo da rodovia Transamazônica. Com o fracasso dessa tentativa, o governo começou a incentivar a ocupação de Rondônia, estado que receberia, na década de 1970, um fluxo migratório maior do que qualquer área fronteiriça no Brasil.

O principal catalisador da atração de imigrantes foram os PIC's (Projetos Integrados de Colonização) ao longo da rodovia BR-364 (BECKER, 1990), que viabilizou a intensa mobilidade horizontal da população, tanto intra como inter-regional. A colonização ao longo da BR-364 fez com que Rondônia tivesse um desenvolvimento extraordinário em termos 
populacionais, tendo seu número de habitantes aumentado $604 \%$ no período 1960 - 80 (BARCELLOS \& COSTA, 1991).

A maior parte dos municípios do estado de Rondônia apresenta taxas elevadíssimas de incremento populacional, algumas superiores a $1000 \%$ no período 1970- 80, como por exemplo, Cacoal (5.536\%), Ji-Paraná (1.272\%), Pimenta Bueno (1.046\%). Ainda referente a esse aspecto, em todas as Unidades da Federação a população rural cresceu em ritmo mais lento que a urbana, exceto em Rondônia, com um crescimento relativo de 410\%, superior aos 284\% registrados pela população urbana (BARCELLOS \& COSTA, 1991).

\section{Análise dos dados dos Censos Demográficos}

Tabela 1: Migração Espírito Santo - Rondônia e vice-versa (Censos 1960, 1970, 1980, 1991 e 2000)

\begin{tabular}{|c|c|c|c|c|}
\hline \multirow[t]{2}{*}{ Censos } & \multirow[t]{2}{*}{ Fluxos } & \multicolumn{2}{|l|}{ Sexo } & \multirow[t]{2}{*}{ Total } \\
\hline & & Masculino & Feminine & \\
\hline \multirow{3}{*}{1960} & ES-RO & 25 & 4 & 29 \\
\hline & RO-ES & 11 & 3 & 14 \\
\hline & Saldo para RO & 14 & 1 & 15 \\
\hline \multirow{3}{*}{1970} & ES-RO & 559 & 455 & 1.014 \\
\hline & RO-ES & 12 & 7 & 19 \\
\hline & Saldo para RO & 547 & 438 & 995 \\
\hline \multirow{3}{*}{1980} & ES-RO & 17.372 & 15.393 & 32.765 \\
\hline & RO-ES & 149 & 130 & 279 \\
\hline & Saldo para RO & 17.223 & 15.263 & 32.486 \\
\hline \multirow{3}{*}{1991} & ES-RO & 40.591 & 35.077 & 75.668 \\
\hline & RO-ES & 559 & 512 & 1071 \\
\hline & Saldo para RO & 40.032 & 34.565 & 74.597 \\
\hline \multirow{3}{*}{2000} & ES-RO & 43.646 & 39.834 & 83.480 \\
\hline & RO-ES & 1415 & 1.530 & 2.945 \\
\hline & Saldo para RO & 42.231 & 38.304 & 80.535 \\
\hline
\end{tabular}

De acordo com os dados apresentados pelos censos, é possível perceber o incremento década a década da presença capixaba em Rondônia. Pelos fatores já expostos que caracterizam a atração deste estado - os PIC's e o eixo rodoviário proporcionando um deslocamento mais adequado - é possível entender por que os camponeses capixabas preferiram este estado à outros, nos quais as terras também seriam de baixo valor - norte de 
Mato Grosso, oeste do Maranhão, sudeste do Pará, áreas inclusive mais próximas ao Espírito Santo.

O intervalo intercensitário que mais se destaca no período abordado é 1980-91, quando chegaram a Rondônia 42.111 capixabas. Em seu limiar, os fluxos migratórios procedentes dos estados do Espírito Santo e Minas Gerais respondiam por 66\% do total de migrantes do Sudeste presentes na região norte (BARCELLOS \& COSTA, 1991).

No período 1981-84, a população absoluta de RO dobrou e seu índice migratório de $16 \%$ ao ano durante a década de 1980 é o maior que se verificou no país em toda sua história, com exceção de Brasília (BARCELLOS \& COSTA, 1991).

O modelo interpretativo clássico, sustentado no binômio repulsão-atração, e baseado numa abordagem microeconômica que enxerga os indivíduos como dotados de capacidade para fazer escolhas racionais, decidindo migrar na expectativa de ter retorno positivo, principalmente financeiro, parece não ser o único indicado para tentativas de compreensão do porquê os capixabas deixaram seu estado para fazer parte do processo de ocupação do estado de Rondônia.

Segundo a tipologia proposta por Tilly (1978), o caráter distintivo da migração de capixabas para a Amazônia meridional e Rondônia é aquela em cadeia, posteriormente sucedida pela aplicação da noção de rede. Ela envolve o deslocamento de indivíduos motivados por uma série de arranjos e informações fornecidas por parentes e conterrâneos já instalados no local de destino. As informações nesse caso, versavam sobretudo em relação às qualidades que foram positivamente valoradas pelos primeiros capixabas a chegarem a Rondônia e através de cartas contavam a seus parentes e conterrâneos sobre as maiores extensões de terras disponíveis, a topografia mais favorável, as chuvas mais volumosas e regulares, a terra mais fértil que proporcionava grande produtividade, etc.

\section{Os fluxos}

Uma das ligações entre o Espírito Santo e Rondônia se traduz na linha de ônibus que parte de Colatina com destino a Porto Velho e vice-versa. Existe um consórcio formado por seis empresas - Águia Branca, Eucatur, Gontijo, Itapemirim, Pretti e Real Norte responsáveis por partidas diárias para o estado amazônico. 
Pesquisas de campo ${ }^{11}$ conduzidas pelo autor em 2007 indicaram que haviam, porém, épocas distintas no que tange à freqüência. Nos meses de abril, maio, junho, época da colheita do café em ambos os estados, o fluxo era baixo, fazendo com que algumas partidas fossem aglutinadas a cada dois dias. Já o mês de julho, somado ao período compreendido entre o final de novembro e fevereiro são épocas de alta procura por passagens, o que demanda a saída de carros extra na linha. Tais alternâncias entre épocas de alta e baixa demanda por transporte entra as duas áreas são motivadas tanto pelo período de concomitância às férias escolares como pela maior carga de trabalho no campo oriunda da safra do café, principalmente sua variedade robusta, o qual o Espírito Santo e Rondônia ocupam posições de destaque no país ${ }^{12}$.

O itinerário do deslocamento dura aproximadamente 48 horas, e passa por cinco estados: Espírito Santo, Minas Gerais, Goiás, Mato Grosso e Rondônia. São três paradas diárias, para café da manhã, almoço e jantar com tempo previsto de 15 a 30 minutos cada uma delas.

Os pontos de embarque são, além de Colatina, João Neiva, Vitória, Venda Nova do Imigrante (ES) e Belo Horizonte (MG). Já em Rondônia os desembarques acontecem nas cidades de Pimenta Bueno, Cacoal, Presidente Médici, Ouro Preto, Ji-Paraná, Jaru, Ariquemes e Porto Velho. Além do transporte realizado pelas empresas integrantes do consórcio, existem ainda outras opções - excursões de grupos auto organizados, etc.

Um dos indícios que reforçam a tese da numerosidade da presença capixaba em Rondônia pode estar no fato que de todas as 27 capitais brasileiras, apenas três ligam-se direta e diariamente à Colatina: Vitória (à $135 \mathrm{Km}$ ), naturalmente por ser a capital do Espírito Santo, São Paulo ( à cerca de $1000 \mathrm{Km}$ ), o maior centro econômico, financeiro, industrial e cidade mais populosa do país e Porto Velho-RO. A ligação direta entre Colatina, investida na qualidade de município polo do Noroeste capixaba, e Porto Velho, evidencia a magnitude dessa emigração principalmente quando se põe em relevo a distância do percurso aproximadamente $3700 \mathrm{Km}$.

\footnotetext{
11 Transeuntes entre os dois estados responderam questionários semiabertos, em abordagens nos terminais rodoviários de Colatina e Vitória, ES.

12 Disponível em http://www.agricultura.gov.br/assuntos/politica-agricola/cafe/cafeicultura-brasileira . Acesso em 15/12/18.
} 
Figura 1: Painel informativo da Viação Itapemirim no Terminal Rodoviário de Colatina.

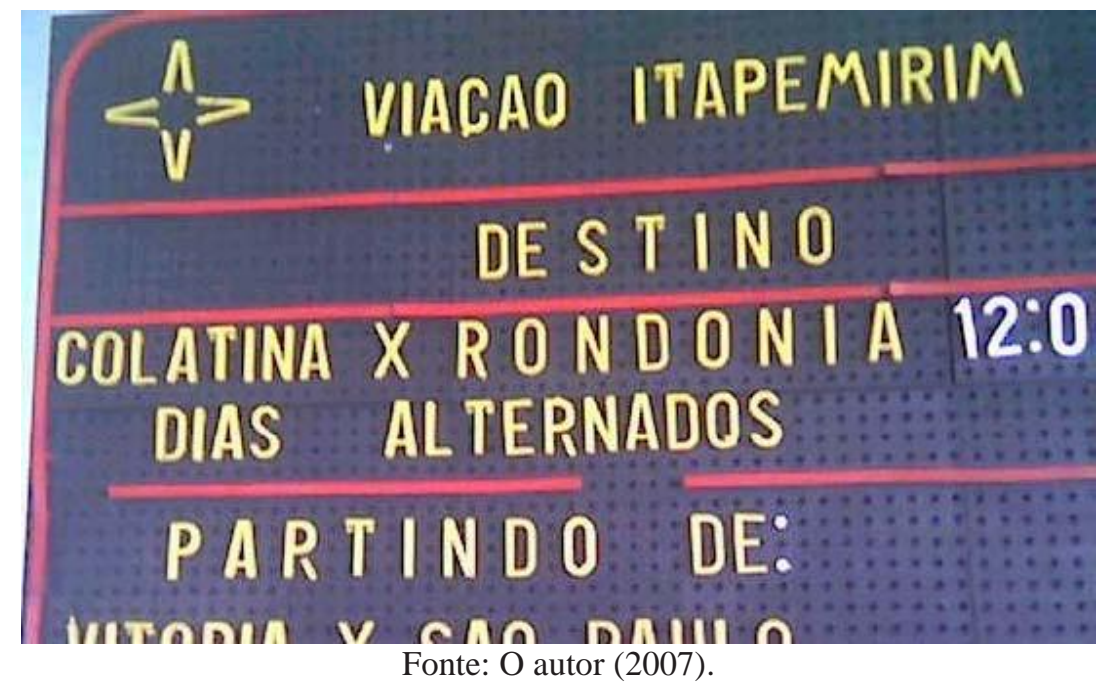

Se hoje uma viagem de 48 horas parece cansativa, os primeiros capixabas emigrados para a Amazônia meridional chegaram a enfrentar jornadas de uma semana, em caminhões (paus-de-arara) por estradas sem pavimentação, recém-abertas, sujeitos a todo tipo de sorte, conforme relatos obtidos de passageiros entre os dois estados.

Nos últimos anos, após a inauguração de aeroportos regionais em cidades polo do interior de Rondônia (Vilhena, Cacoal e Ji-Paraná) tem aumentado o número de passageiros que viajam entre os dois estados por via aérea. A companhia Azul Linhas Aéreas liga as três cidades à Cuiabá-MT.

A migração de capixabas para Rondônia, embora comprovadamente numerosa e portadora de inúmeros efeitos para ambos os estados é academicamente retratada de forma marginal. Pensemos aos efeitos como as transformações na agropecuária (introdução da lavoura cafeeira), as alterações sócio demográficas (em termos de etnia, a razão de sexos e a estrutura etária), religiosidade (introdução do luteranismo) e línguas alóctones (pomerano) (LINK, 2004), conforme mencionado antes. 
Figura 2: Nome do time de futebol da Linha 7, a partir de Cacoal-RO.

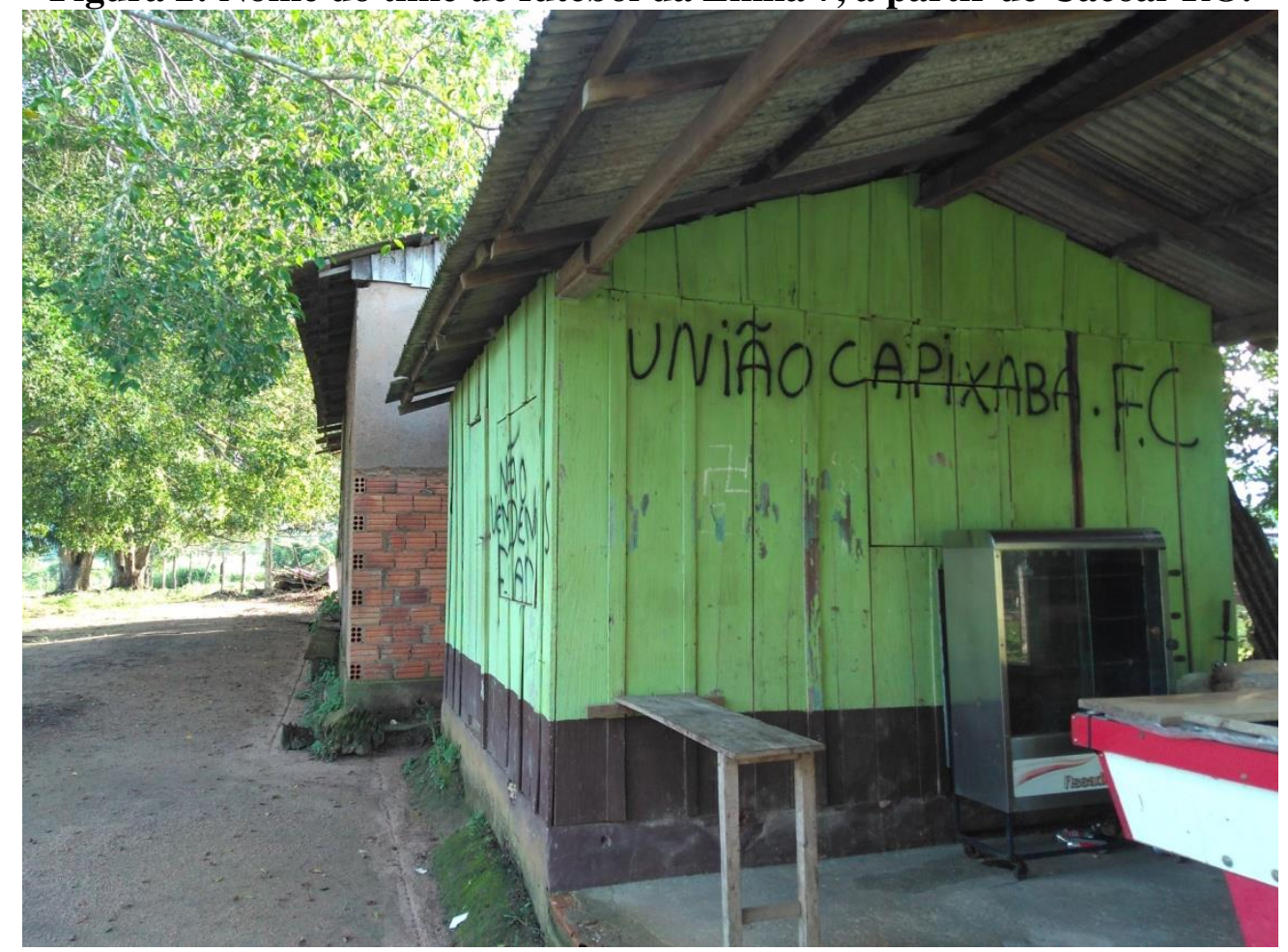

Fonte: o autor (2008).

Entretanto, houve em Rondônia a formação de intensos movimentos migratórios intraregionais. A rápida depredação dos recursos naturais do centro do estado, exaurindo o solo e os recursos hídricos, contribuiu para tal, como apontado por Binsztok (2008). De acordo com o autor, tais movimentos estão ultrapassando as migrações provenientes de outras unidades da federação, incluídas aquelas oriundas do Espírito Santo. Tem sido verificado que grupos de agricultores têm se direcionado para novas frentes, no norte de Mato Grosso, na divisa com o Amazonas e com o Acre ou outros municípios do estado (BINSZTOK, 2008).

Tabela 2: Migração Espírito Santo - Rondônia e vice-versa (Censos 1960, 1970, 1980, 1991 e 2000)

\begin{tabular}{llll}
\hline UF & Destino & Origem & Saldo \\
\hline Rondônia & 2.116 & 7.754 & -5.638 \\
\hline Minas Gerais & 38.516 & 29.529 & 8.987 \\
\hline Rio de Janeiro & 28.927 & 18.250 & 10.677 \\
\hline Bahia & 31.743 & 14.447 & 17.296 \\
\hline
\end{tabular}

Fonte: IBGE, Censo Demográfico de 2000. 
A tabela 2 permite verificar que, a luz do que afirma Binsztok (2008), a partir dos anos 1990 a força do fluxo migratório entre os dois estados diminuiu. Contudo, no período intercensitário considerado, Rondônia, não obstante a distância em relação ao Espírito Santo, era a única unidade da federação para quem o estado capixaba perdia população. Nesse mesmo período, o saldo migratório em relação aos estados limítrofes (Bahia, Rio de Janeiro e Minas Gerais) era positivo para o Espírito Santo.

Os dados do Censo Demográfico de 2010 também trazem indicativos interessantes que permitem verificar a ainda forte ligação migratória entre os dois estados. Ao considerar os brasileiros que em 2010 moravam em Rondônia, mas que declararam residir em outros estados na data de referência de 31/07/2005, além dos estados limítrofes do Acre, Amazonas e Mato Grosso, o Espírito Santo é superado apenas por São Paulo e Paraná, posicionando-se assim, nesse quinquênio considerado como o $6^{\circ}$ maior emissor para o estado amazônico.

\section{Tabela 3: Brasileiros natos por unidade da federação de nascimento para Rondônia} Residência em $2010 \quad$ Onde residiam em 31.07.2005

Rondônia Acre Amazonas $\begin{aligned} & \text { Espírito } \\ & \text { Santo }\end{aligned}$ São Paulo Paraná Mato Grosso

$\begin{array}{llllll}3.387 & 6.686 & 2.397 & 4.189 & 6.018 & 13.786\end{array}$

Fonte: IBGE, Censo Demográfico de 2010

Já quando consideramos os brasileiros residentes no Espírito Santo em 2010, mas que afirmaram estar vivendo em outro estado em 2005, de Rondônia veio o $5^{\mathrm{o}}$ maior contingente, superado neste caso pelos três estados limítrofes (Bahia, Minas Gerais e Rio de Janeiro) e São Paulo. Perde-se nesse caso a naturalidade com que o fato de compartilhar divisas pode ser usado para explicar ligações migratórias significativas, como aquelas existentes entre Espírito Santo e Rondônia. O quadro 4 expressa os números. 
Tabela 4: Brasileiros natos por unidade da federação de nascimento para o Espírito Santo

Residência em 2010 Onde residiam em 31.07.2005

\begin{tabular}{llllll} 
Espírito Santo & Rondônia & Bahia & Minas Gerais & Rio de Janeiro & São Paulo \\
\cline { 2 - 6 } & 2.231 & 11.010 & 21.605 & 17.788 & 7.339
\end{tabular}

Fonte: IBGE, Censo Demográfico de 2010

O pico máximo da população capixaba emigrada em Rondônia foi computado pelo IBGE no Censo de 2000, quando naquele estado, em uma população total de 1.376.611 habitantes, 83.480 eram capixabas, total esse que àquela altura era superado apenas por mineiros e paranaenses. Embora quantitativamente esses estados tenham emitido mais migrantes para Rondônia, a perda desses habitantes teve um significado maior para o Espírito Santo. Os capixabas que para lá se dirigiram correspondiam a cerca de $15 \%$ dos nascidos no estado que migraram. Para o Paraná, estado com maior presença em termos absolutos em Rondônia, eles equivaliam a $9 \%$.

O Censo de 2010 apontou o enfraquecimento do fluxo, menos alimentado que outrora, tendo havido diminuição da presença de capixabas em Rondônia. Do pico citado de 83.400 indivíduos em 2000, o total passa a 69.584. Algumas hipóteses explicativas são:

1) a mortalidade, visto o perfil etário das famílias emigradas nos anos 70 e 80, compostas por pessoas de meia idade e idosas;

2) novas migrações para áreas de estados limítrofes à Rondônia, como em efeito, Binsztok (2008) diagnostica e descreve esse processo em suas pesquisas.

Por fim e para clarificar, existe uma corrente migratória de retorno no sentido Rondônia-Espírito Santo, mas aventar sua existência como hipótese para explicar a diminuição da presença dos capixabas no estado amazônico não é suficiente, pois como vimos, o saldo migratório ainda é favorável à Rondônia.

\section{CONSIDERAÇÕES FINAIS}

O fator distância tem uma significação fundamental para atribuirmos um grau de importância ao deslocamento realizado pelos capixabas para Rondônia. Nesse contexto, cabe esclarecer que ele age como um elemento de seletividade, pois quanto mais aumenta a distância do percurso, maiores devem ser os gastos em relação a ela. Dessa forma, indivíduos com características diferentes, tendem a perceber a migração de forma diferenciada. 
Geralmente, aqueles com maior renda ou melhor nível de educação migram percorrendo maiores distâncias, por que estão mais capacitados para pagar os custos mais elevados de uma mudança para um local mais afastado. Espera-se que quanto maior a distância percorrida maiores sejam os ganhos a serem percebidos. Entretanto, quanto maiores forem as distâncias menor será a magnitude dos fluxos.

Entre os quatro estados que mais contribuíram para o saldo migratório de Rondônia Paraná, Minas Gerais, São Paulo e Espírito Santo - este último merece atenção especial, pois é o que se situa mais afastado do estado amazônico e possui o segundo menor número de habitantes.

Segundo Castiglioni (1984), a variável distância pode ser entendida no estudo das migrações a partir de um modelo gravitacional (ou de interação espacial), juntamente com outras variáveis diretamente mensuráveis relativas ao espaço geográfico - população e superfície. Nesse sentido, a migração é diretamente proporcional aos afetivos de população da região de origem e de destinação, e inversamente proporcional à distância.

Por outro lado, o efeito da distância sobre os fluxos migratórios pode ser minimizado ou anulado, se levarmos em consideração a teoria de Stouffer (apud CASTIGLIONI, 1984, p.66). Esse pesquisador argumenta que a mobilidade não é uma função da distância diretamente, mas sim que os deslocamentos a uma distância determinada são diretamente proporcionais ao número de possibilidades de trabalho situadas no lugar de destinação e inversamente proporcionais ao número de fatores intermediários que se situam entre as duas zonas.

A explicação de Stouffer nos parece bem apropriada para entender as razões de uma distância tão grande entre o lugar de origem e de destino dos emigrantes capixabas. Ressaltase no fim da análise de todas essas variáveis, que considerando a distância, a saída de capixabas para Rondônia trouxe muitos efeitos de ordem socioeconômica demográfica para o Espírito Santo. De maneira diretamente proporcional certamente os capixabas constituíram-se como um dos grupos que mais portou alterações de mesma ordem para o estado de Rondônia.

Qualquer que seja a interpretação aceita como mais abrangente na explicação do fenômeno abordado neste artigo - o clássico binômio atração-repulsão, a mobilidade induzida pela expansão do capital, a resposta a interesses geopolíticos e estratégicos nacionais ou ainda a soma de todos eles, não muda o fato de que embora seja numerosa e importante para ambos os estados, este seja um fenômeno marginal nos estudos acadêmicos concernentes às migrações internas no Brasil. 


\section{REFERÊNCIAS}

BAHIANA, L.C. O Norte na organização regional do Brasil, In: IBGE. Geografia do Brasil: Região Norte. Rio de Janeiro: IBGE,1991.

BARCELLOS, M.M.; COSTA, W.S. População, In: IBGE. Geografia do Brasil: Região Norte. Rio de Janeiro: IBGE,1991.

BEAUJEU - GARNIER, J. Geografia de população. $2^{\text {a }}$ ed. São Paulo: Ed. Nacional, 1980.

BECKER, Berta. Amazônia. São Paulo: Ed. Ática, 1990.

Amazônia: Geopolítica na virada do III milênio. Rio de Janeiro: Ed. Garamond, 2004.

BECKER,

O.M.S.

Mobilidade

espacial da população: conceitos, tipologia, contextos. In: CASTRO, I.E.; GOMES, P.C.C.; CÔRREA, R.L (orgs.). Explorações geográficas: percursos no fim do século. 1.ed. Rio de Janeiro: Bertrand Brasil, 1997, 367p.

BINSZTOK, J. As diferenças socio-espaciais dos produtores familiares dedicados ao cultivo do café na Amazônia. Barcelona (Espanha): Revista Electrónica de Geografía y Ciencias Sociales, 2006. Disponível em: http://www.ub.es/geocrit/sn/sn-218-02.htm. Acesso em 09/04/2007.

CAMPOS JUNIOR., C.T. A Formação da Centralidade de Colatina. IHGES: Vitória, 2004.

CASTIGLIONI, A.H. Migrations internes au Bresil (Thèse en Démographie). Louvain (Belgique), Universitè Catholique de Louvain, 1984.

GAUDEMAR, J.P. Mobilidade do trabalho e acumulação do capital. Lisboa: Editorial Estampa, 1977.

INSTITUTO BRASILEIRO DE GEOGRAFIA E ESTATÍSTICA. Áreas de atração e evasão populacional no Brasil no período de 1960/70. Rio de Janeiro: IBGE, 1979.

JACOB, J.K. Cidades irmãs pomeranas: Vila Pavão (ES) e Espigão d'Oeste (RO). Nova Venécia-ES: Cricaré, 2011.

LINK, R.S. Luteranos em Rondônia: o processo migratório e o acompanhamento da Igreja Evangélica de Confissão Luterana no Brasil (1967-1987). São Leopoldo: Escola Superior de Teologia, Instituto Ecumênico de Pós-Graduação, 2004.

MELLO, Neli Aparecida; THÉRY, Henry. Atlas do Brasil: disparidades e dinâmicas do território. São Paulo: Edusp, 2005.

MORIN, E. Ciência com Consciência. Rio de Janeiro: Bertrand Brasil, 2002.

MOURA, H. A. Nota Prévia, IN: Migração Interna - textos selecionados, Tomo 1. Fortaleza: Banco do Nordeste do Brasil, 1980. p. 11-16. 
NAÇÕES UNIDAS. Manual VI - Métodos de medição da Migração Interna, IN: Migração Interna - textos selecionados, Tomo 1. Fortaleza: Banco do Nordeste do Brasil, 1980.

PATARRA, N; CUNHA, J.M. Migração: um tema complexo. São Paulo: São Paulo em Perspectiva, 1987.

PÓVOA NETO, Hélion. Migrações internas e mobilidade do trabalho no Brasil atual. Novos desafios para análise. Revista Experimental, São Paulo, n.2, p.11-24, março de 1997.

RAVENSTEIN, E. G. The laws of migration, IN: Migração Interna - textos selecionados, Tomo 1. Fortaleza: Banco do Nordeste do Brasil, 1980.

RONDÔNIA, GOVERNO DO ESTADO DE. História sobre Rondônia. Disponível em http://www.rondonia.ro.gov.br/conteudo.asp?id=180. Acesso em 13/04/2008.

SANTOS, Milton. A natureza do espaço. São Paulo: EDUSP, 2004.

Técnica, Espaço, Tempo: Globalização e meio técnico-científico-informacional. São Paulo: EDUSP, 2008.

SANTOS, Regina Bega. Migração no Brasil. São Paulo: Scipione, 1994.

SAUVY, A. Elementos de Demografia. Rio de Janeiro: Zahar Editores, 1979.

TILLY, C. Migration in Modern European History. In: MCNEILL, W.H. \& A.R. S. (orgs.). Human migration, patterns and policies. Indiana University Press, pp. 48-72

VALADÃO, Vanda de Aguiar. Assentamentos e sem-terra: a importância do papel dos mediadores. Vitória: Edufes, 1999.

Recebido em Agostode 2017

Aprovado em Dezembrode 2018

Publicado em Fevereiro de 2018 